\section{Hipoplasia prosencefálica em bezerro: relato de caso}

\author{
Prosencephalic hypoplasia in a calf: case report
}

Saulo Andrade Caldasi*, Vivian de Assunção Nogueira², Luana Vilela Lopes Caldas³ ${ }^{3}$ Nathália da Silva Carvalho ${ }^{4}$, Lucinéia Costa Oliveira ${ }^{5}$, Vinicius Vasconcelos da Cruz Gonçalo6, Marcela Próspero Rodrigues Pinto \& Tiago da Cunha Peixoto ${ }^{7}$

'Médico veterinário, Dr, Docente. Departamento de Medicina e Cirurgia Veterinária, Universidade Federal Rural do Rio de Janeiro - UFRRJ, Seropédica, RJ, Brasil

2Médica veterinária, Dr., Docente. Departamento de Epidemiologia e Saúde Pública, Universidade Federal Rural do Rio de Janeiro - UFRRJ, Seropédica, RJ, Brasil

${ }^{3}$ Médica veterinária autônoma. Rio de Janeiro, RJ, Brasil

${ }^{4}$ Graduanda em Medicina Veterinária. Universidade Federal Rural do Rio de Janeiro - UFRRJ, Seropédica, RJ, Brasil

${ }^{5}$ Médica veterinária. Programa de Pós-graduação em Medicina Veterinária, Universidade Federal Rural do Rio de Janeiro UFRRJ, Seropédica, RJ, Brasil

${ }^{6}$ Médico veterinário, Residente na Área de Clínica e Cirurgia de Grandes Animais. Universidade Federal Rural do Rio de Janeiro - UFRRJ, Seropédica, RJ, Brasil

${ }^{7}$ Médicos veterinários, Dr, Docentes. Departamento de Anatomia, Patologia e Clínicas Veterinárias, Escola de Medicina Veterinária e Zootecnia, Universidade Federal da Bahia - UFBA, Salvador, BA, Brasil

\section{Resumo}

O objetivo deste estudo é relatar um caso de hipoplasia prosencefálica, caracterizada pela ausência das partes rostrais dos hemisférios cerebrais, em um bezerro mestiço. Durante o exame necroscópico evidenciou-se ausência de meninges, com região prosencefálica (telencéfalo e diencéfalo) de tamanho reduzido e rudimentar, sem divisão dos hemisférios cerebrais e circunvoluções cerebrais pouco definidas. A causa de malformação em fetos de animais domésticos, raramente é determinada e, além da hereditariedade, vários agentes infecciosos e tóxicos podem causar anomalias congênitas.

Palavras-chave: malformações congênitas, sistema nervoso, bovino, patologia.

\section{Abstract}

Our study aimed to report a case of prosencephalic hypoplasia, a condition in which the rostral end of the brain hemispheres is absent, in a crossbreed calf. Grossly, the prosenchephalic (telencephalon and diencephalon) region of the brain was poorly developed and reduced in size; the brain hemispheres were absent, and brain convolutions were poorly delimited. Etiology of this condition in domestic animals is unknown. Hereditary factors and toxic and infectious agents may lead to congenital defects.

Keywords: congenital malformations, nervous system, bovine, pathology.

\section{Introdução}

Malformações ou defeitos congênitos são alterações que ocorrem no período da gestação (Noden \& De Lahunta, 1990). Durante a fase embrionária, o embrião está susceptível a diversos agentes teratogênicos de origem genética (mutações cromossômicas) ou ambiental (agentes infecciosos, físicos, químicos, nutricional, intoxicações por plantas ou fármacos) (Rosa, 1990). Devido à complexidade de formação e diferenciação, o sistema nervoso central é altamente susceptível aos agentes teratogênicos e consequentemente às alterações congênitas (Maxie \& Youssef, 2007; Zachary, 2013). Essas alterações podem acometer todas as espécies domésticas, tendem a acontecer de forma esporádica e refletem em abortos e perdas econômicas aos produtores (Khodakaram-Tafti \& Ikede, 2005).

A hipoplasia prosencefálica é caracterizada pela ausência das partes rostrais dos hemisférios cerebrais, porém o tronco encefálico permanece preservado. Essa anomalia é provocada por uma disrafia encefálica, ou seja, um defeito no fechamento do sítio I do tubo neural, e não deve ser confundida com anencefalia (ausência total do encéfalo) (Zachary, 2013). Essa alteração é incompatível com a vida, porém, há relatos de animais que nascem com hipoplasia prosencefálica, se locomovem e sobrevivem por algum período de tempo (Summers et al., 1995).

\section{BJ $\mathrm{M}$

Como citar: Caldas, S. A., Nogueira, V. A., Caldas, L. V. L., Carvalho, N. S., Oliveira, L. C., Gonçalo, V. V. C., Pinto, M. P. R., \& Peixoto, T. C. (2017). Hipoplasia prosencefálica em bezerro: relato de caso. Brazilian Journal of Veterinary Medicine, 39(4), 275-278. doi: 10.29374/2527-2179. bjvm018917

Fonte de financiamento: Nenhuma.

Conflito de interesses: Os autores declaram não haver conflito de interesses que precisam ser informados.

Recebido: Agosto 15, 2017.

Aceito: Dezembro 12, 2017.

O estudo foi realizado em uma propriedade particular na Cidade de Barra do Piraí, RJ, Brasil.

\section{*Correspondência}

Saulo Andrade Caldas

Departamento de Medicina e Cirurgia Veterinária, Universidade Federal Rural do Rio de Janeiro - UFRRJ

Rod. BR 465, Km 47 (antiga Rio-São Paulo) CEP 23890-000 - Seropédica (RJ), Brasil E-mail:sauloacaldas@homail.com 
Os casos de hipoplasia prosencefália são escassos na literatura veterinária e são pouco relatados na espécie bovina (Pavarini et al., 2008; Mottaghian et al., 2015). O objetivo deste estudo é descrever um caso de hipoplasia prosencefálica em um bezerro mestiço no Estado do Rio de Janeiro.

\section{Histórico}

Em janeiro de 2010, um bezerro mestiço, macho, advindo de gestação normal de 9 meses proveniente de monta natural entre vaca mestiça com 7 anos de idade e touro Brahman de 8 anos, foi atendido por um Médico Veterinário com histórico de contrações musculares e incapacidade de levantar-se após o nascimento.

O animal pertencia a um rebanho com 35 cabeças, criado em regime extensivo e mantido em pastagem de Brachiaria brizantha e B. decumbens em uma propriedade localizada no município de Barra do Piraí, RJ. Devido ao prognóstico desfavorável, o proprietário optou pela eutanásia 8 horas depois do nascimento para elucidação diagnóstica. Após a morte, o bezerro foi encaminhado ao Setor de Anatomia Patológica da Universidade Federal Rural do Rio de Janeiro (UFRRJ) para ser necropsiado.

\section{Discussão}

Durante a visita à fazenda, o proprietário relatou que os outros dois bezerros paridos previamente pelo mesmo animal, bem como os outros descendentes do touro não apresentaram quaisquer alterações clínicas e que, casos semelhantes a esse nunca ocorreram na propriedade. Além disso, os progenitores encontravam-se sadios e sem alterações morfológicas visíveis. A vaca apresentava resultados negativos para brucelose, rinotraqueíte infecciosa bovina (IBR) e diarreia viral bovina (BVD).

Ao exame físico do bezerro observou-se cegueira, enotou-se que parte das contrações musculares eram tentativas sem êxito de movimentação dos membros. Durante o exame necroscópico, foi evidenciado fechamento incompleto dos ossos do crânio e, à abertura deste, verificou-se ausência de meninges, com região prosencefálica (telencéfalo e diencéfalo) de tamanho reduzido e rudimentar, sem divisão dos hemisférios cerebrais e circunvoluções cerebrais pouco definidas (Figura 1).

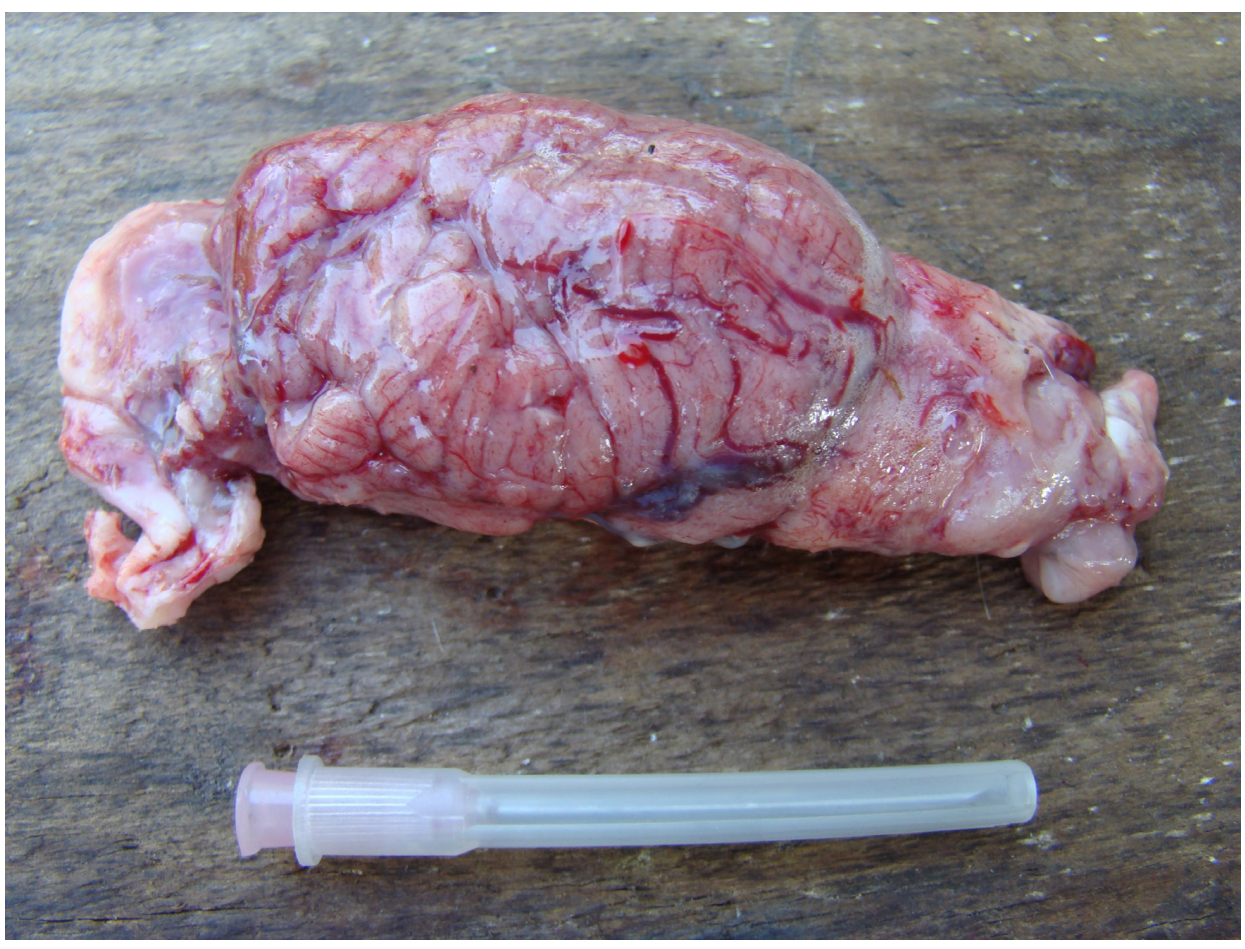

Figura 1. Região prosencefálica (telencéfalo e diencéfalo) de tamanho reduzido e rudimentar, sem divisão dos hemisférios cerebrais e circunvoluções cerebrais pouco definidas. 
O mesencéfalo e rombencéfalo encontravam-se sem alterações macroscópicas significativas. O diagnóstico de hipoplasia prosencefálica baseou-se no histórico e no quadro clínico-patológico.

Esta malformação caracteriza-se por ausência de partes dos hemisférios cerebrais na porção rostral que podem estar presentes de modo muito sutil. Nessa anomalia, o tronco encefálico encontra-se preservado em níveis variados (Zachary, 2013).

A cegueira observada no bezerro com hipoplasia prosencefálica está associada à escassez de telencéfalo e diencéfalo, regiões anatômicas em que o sistema visual está localizado (Mottaghian et al., 2015). Apesar da não realização de exames sorológicos no bezerro, o resultado negativo da progenitora para Diarréia Viral Bovina (BVD) sugere que a alteração não está associada a um efeito teratogênico ambiental (infeccioso).

A causa de malformação em fetos de animais domésticos, raramente é determinada e, além da hereditariedade, vários agentes infecciosos e tóxicos podem causar diversas anomalias congênitas. As anormalidades anatômicas mais frequentes são advindas de defeitos no tubo neural, principalmente no seu fechamento que se inicia em quatro pontos distintos (sítios). Pavarini et al. (2008), em um estudo retrospectivo de anomalias congênitas em fetos bovinos, sugeriram a associação de um caso de hipoplasia prosencefálica a genes autossômicos recessivos, uma vez que não foi encontrado nenhum agente etiológico envolvido. Defeitos no fechamento do tubo neural (disrafia) também podem causar malformação no tecido ósseo e tecidos moles sobrepostos.

Os defeitos disráficos podem ser exemplificados por anencefalia, quando ocorre defeito no fechamento do sítio II ou IV, hipoplasia prosencefálica, crânio bífido ou espinha bífida, quando o defeito ocorre no sítio I (Fiss, 2009; Zachary, 2013; Summers et al., 1995).

Anomalias congênitas apresentam distribuição mundial e podem causar aborto ou morte neonatal, o que leva a perdas reprodutivas importantes (Thurmond \& Picanso, 1990; Khodakaram-Tafti \& Ikede, 2005; Pimentel et al., 2007). No Brasil, casos de anomalias congênitas já foram descritas em búfalos (Schild et al., 2003), caprinos (Schmidt \& Oliveira, 2004; Pimentel et al., 2007), ovinos (Nóbrega Junior et al., 2005) e bovinos (Santos et al., 2005).

Apesar de ser incompatível com a vida, parte dos animais com hipoplasia prosencefálica pode nascer e até mesmo sobreviver por algum tempo. Há relatos de até 96 horas de sobrevivência. (Summers et al., 1995; Mottaghian et al., 2015), entretanto, no presente caso, optou-se pela eutanásia pelo fato do bezerro apresentar cegueira, não conseguir ficar em estação e apresentar espasmos musculares durante a tentativa de locomoção.

\section{Conclusão}

Os dados anatomopatológicos do presente caso permitiram o diagnóstico de hipoplasia prosencefálica, provavelmente associada a genes autossômicos recessivos, uma vez que agentes etiológicos não foram identificados.

\section{Referências}

Fiss, L. (2009). Hidranencefalia e hipoplasia cerebelar congênita em búfalos Murrah (Dissertação de mestrado). Universidade Federal de Pelotas, Pelotas.

Khodakaram-Tafti, A., \& Ikede, B. O. (2005). A retrospective study of sporadic bovine abortions, stillbirths, and neonatal abnormalities in Atlantic Canada, from 1990 to 2001. The Canadian Veterinary Journal, 46(7), 635637. PMid:16152720.

Maxie, M. G., \& Youssef, S. (2007). Nervous system. In M. G. Maxie (Ed.), Jubb, Kennedy and Palmer's: pathology of domestic animals (5th ed., Vol. 1, pp. 298-322). Philadelphia: Saunders Elsevier.

Mottaghian, P., Gharebaghy, A., Fatemehetemadi, A. A., \& Asghari, A. (2015). Clinical presentation of prosencephalic hypoplasia in a live Holstein dairy calf. International Journal of Biology. Pharmacy and Allied Sciences, 4(3), 1058-1063.

Nóbrega Junior, J. E., Riet-Correa, F., Nóbrega, R. S., Medeiros, J. M., Vasconcelos, J. S., Simões, S. V. D., \& Tabosa, I. M. (2005). Mortalidade perinatal de cordeiros no semi-árido da Paraíba. Pesquisa Veterinária Brasileira, 25(3), 171-178. http://dx.doi.org/10.1590/50100-736X2005000300008.

Noden, D. M., \& De Lahunta, A. (1990). Embriologia de los animales domesticos (p. 399). Zaragoza: Acribia.

Pavarini, S. P., Sonne, L., Antoniassi, N. A. B., Santos, A. S., Pescador, C. A., Corbellini, L. G., \& Driemeier, D. (2008). Anomalias congênitas em fetos bovinos abortados no Sul do Brasil. Pesquisa Veterinária Brasileira, 28, 149-154. 
Pimentel, L. A., Correa, F. R., Gardner, D., Panter, K. E., Dantas, A. F. M., Medeiros, R. M. T., Mota, R. A., \& Araújo, J. A. S. (2007). Mimosa tenuiflora as a cause of malformations in ruminants in the Northeastern Brazilian semiarid rangelands. Veterinary Pathology, 44(6), 928-931. http://dx.doi.org/10.1354/vp.44-6-928. PMid:18039908.

Rosa, J. S. (1990). Malformações congênitas em ovinos (p. 13). Brasília: Centro Nacional de Pesquisa de Caprinos, Empresa Brasileira de Pesquisa Agropecuária.

Santos, M. S., Adami, M., Oliveira, A. C. G., Souza, M. S., Silva, R. D. G., Pinto, M. G. F., Almeida, A. E. F. S., \& Faria, M. M. M. D. (2005). Diprosopo em bezerro: relato de caso. Revista Brasileira de Saúde e Produção Animal, 6(1), 24-30.

Schild, A. L., Soares, M. P., Dame, M. C., Portianski, E. L., \& Riet-Correa, F. (2003). Arthrogriposis in Murrah buffaloes in southern Brazil. Pesquisa Veterinária Brasileira, 23(1), 13-16. http://dx.doi.org/10.1590/50100-736X2003000100003.

Schmidt, V., \& Oliveira, R. T. (2004). Artrogripose em caprino: relato de caso. Arquivo Brasileiro de Medicina Veterinária e Zootecnia, 56(4), 438-440. http://dx.doi.org/10.1590/S0102-09352004000400003.

Summers, B. A., Cummings, J. F., \& Delahunta, A. (1995). Veterinary neuropathology (p. 527). Baltimore: Mosby.

Thurmond, M. C., \& Picanso, J. P. (1990). A surveillance system for bovine abortion. Preventive Veterinary Medicine, 8(1), 41-53. http://dx.doi.org/10.1016/0167-5877(90)90021-9.

Zachary, J. F. (2013). Nervous system. In M. D. McGavin \& J. F. Zachary, Pathologic basis of veterinary disease (5th ed., pp. 798-799). Missouri: Mosby Elsevier. 